\title{
Morpho- and Histometric Evaluations on the Testis and Epididymis in Buffalo Bulls During the Different Reproductive Seasons
}

\author{
Silvana Arrighi ${ }^{*}, 1$ Giampaolo Bosi ${ }^{1}$, Debora Groppetti ${ }^{2}$ and Fausto Cremonesi ${ }^{2}$ \\ ${ }^{I}$ Department of Veterinary Science and Technologies for Food Safety, Laboratory of Anatomy; ${ }^{2}$ Department of \\ Veterinary Clinical Science, Reproduction Unit, Faculty of Veterinary Medicine, Università degli Studi di Milano, \\ Milan, Italy
}

\begin{abstract}
Some morphometric parameters of the buffalo gonad and epididymis were compared in the mating (late autumn-winter) versus non-mating (late spring to the beginning of autumn) seasons. Organs from mature bulls of proven fertility were collected at slaughtering in February and September and used for this study. Testicular and epididymal diameters and weights were measured. The diameters of the testicular seminiferous tubules, as well as the diameters of the ductal lumen in sections taken from caput, corpus and cauda, were compared on haematoxylin and eosin-stained sections. The height of epididymal principal cells was also measured, from the basement to the apical membrane. The data obtained in the two seasons were analyzed by ANOVA, co-variating the histometric data for testicular and epididymal weight, respectively. Season-related differences were observed. Testicular and epididymal weights were higher during the mating period, as well as the organ lengths. Spermatogenesis was conserved in the resting period, but the testis showed smaller tubular diameters. In the epididymal caput and corpus the tubular diameters and epithelial cell height were significantly diminished in summer. On the contrary, tubular diameter and epithelial cell height of cauda epididymis increased during the summer, due to accumulation of non-ejaculated spermatozoa. Seasonal variations of genitalia recorded in buffalo bulls could represent an interesting aspect affecting fertility, which might influence the quality of semen and, in turn, the chance of cryopreservation. Morphometric studies of reproductive organs could contribute to better develop the reproductive potential in this species.
\end{abstract}

Keywords: Buffalo bull, epididymis, testis, morphometry, histometry, seasonality.

\section{INTRODUCTION}

The bubaline species is diffuse throughout all the continents and is especially reared in the developing Countries, particularly in Asia. Buffalo in these countries are kept primarily as a source of milk or meat. In Europe, the importance of buffalo breeding is limited to Bulgaria and Italy, in particular the Mediterranean Buffalo (Bubalus bubalus) which is largely bred in the Southern regions of Italy. Its economic importance is chiefly linked to high milk production, which in turn has implications over the Italian dairy industry, thanks to the famous "mozzarella" cheese ${ }^{* *}$. However, the reproductive physiology is a limit to a full buffalo productivity, as fertility is considerably lower in this species than in cattle [1]. Bubaline reproductive physiology is incompletely influenced by domestication and shows peculiarities of sure interest both to the breeder and to the biologist. Reproduction in wild animals is generally seasonal, however, this characteristic gradually diminishes

*Address correspondence to this author at the Dipartimento di Scienze e Tecnologie Veterinarie, per la Sicurezza Alimentare, Laboratorio di Anatomia, Via Trentacoste 2, 20134 Milano, Italy; Tel: +39.0250315741; Fax:+39.0250315746; E-mail: silvana.arrighi@unimi.it

**The Protected Geographical Status (PGS) framework defined in European Union law to protect the names of regional foods designated "mozzarella cheese" as PDO (Protected Designation Origin), and "mozzarella di bufala campana" as Traditional Speciality Guaranteed (TSG or Certificate of Specific Character). with domestication $[2,3]$, which contributes to minimise the effects of season on reproductive activity. The definition of domestication implies the need for controlled breeding, perhaps the most necessary factor for successful domestication. In wild life, seasonality can be interpreted as a natural contraceptive method [4], which restricts the reproductive activity to the optimal time of the year for assuring that births occur at a time that promotes maximal growth and development of the offspring and supports lactation in the mother.

Accordingly, the buffalo has been traditionally regarded as a poor breeder with low reproductive efficiency, characterized by late attainment of puberty and maturity, seasonality of calving, long postpartum anoestrus, poor expression of oestrous signs, low conception rates and long calving intervals [5-7]. A seasonal pattern of reproduction is frequently seen in the bubaline females in some world locations, where annual changes in rainfall determine the availability and quality of feed. In Italy, however, where buffalo are fed with a constant balanced diet, a distinct seasonal reproductive pattern is also found, and the inference from a series of studies is that seasonality is influenced by photoperiod, mediated by melatonin secretion [2]. In fact, the buffalo is a short-day breeder, such as goats and sheep, becoming sexually active in response to decreasing day length in the late summer to early autumn.

Buffalo bulls are capable of breeding throughout the year, but some seasonal fluctuation in reproductive function is evident in most countries where this species is reared 
$[8,9]$, with semen quality being poorer during summer than in winter, especially concerning its freezeability [10] which suggest that summer spermatozoa may be fragile and unable to withstand freezing stress, and semen should be frozen only during winter and spring. Even testosterone blood concentration is influenced by seasonal factors and stimulated by contact with females, whose reproductive activity is considered to be linked to seasonality $[1,11]$. In Italy, in extensive traditional breeding the cyclic ovarian activity is mainly high in autumn, while during spring and early summer it is very low [11]. Accordingly, it appears clear how the traditional reproductive technologies, which are tentatively utilized in the buffalo, demonstrate less efficient compared to the bovine [12].

A morphological study of the testis is mandatory to evaluate the influence that different factors, such as hormonal fluctuations of the photo-neuroendocrine circuit may have on reproductive efficiency which may be a result of seasonal variation [13]. Likely, the morphophysiology of the male gonad is influenced by the pineal and pituitary incretions during the year which consequently may influence spermatic composition [14, 15]. The functions and morphology of the genital tract may also be modified in relation with the sperm maturation events taking place at this level [16, rev. in 17].

Therefore, the aim of this investigation was to evaluate useful parameters to determine the relationship between gonadic physiology and reproductive variation during the mating (Oct/May) versus non-mating season (Jun/Sept). A morpho- and histometric approach has been used, as these methods allow for objective and quantitative evaluations when a comparison is carried on different situations, and to operate statistical analyses on the data obtained either in experimental and in wild conditions $[15,18]$.

\section{MATERIALS AND METHODS}

Organs from eight mature buffalo bulls of proven fertility have been used for this study. Testes and epididymides were collected at slaughtering in February $(\mathrm{n}=4)$ and beginning of September $(\mathrm{n}=4)$, at the Stabilimento Inalca, Ospedaletto Lodigiano (Lodi, Italy) where Mediterranean Italian buffaloes bred in the Middle-Southern regions of Italy are normally slaughtered. Both gonads and epididymides of each animal were evaluated. The testes were gently dissected free from scrotum and analyzed for testicular diameters and weight measurements. The epididymis was separated from the respective testis, total length from caput to cauda and maximum diameter at the tail level were measured, then it was weighed. Small fragments from each sample were fixed in $4 \%$ paraformaldehyde in phosphate buffered saline (PBS), dehydrated in a graded series of ethanol, clarified in xylene and embedded in paraffin. Tissue blocks were cut serially at $4 \mu \mathrm{m}$ thickness, and sections were de-waxed and stained with routine Haematoxylin-Eosin (H\&E) technique for general morphological purposes and histometric studies. The diameters of the testicular seminiferous tubules were measured in 10 cross-sections per sample. Quantitative histometry of epididymis was studied on sections taken from caput, corpus and cauda. The diameters of the ductal lumen were measured, and the height of principal cells was measured from the basement to the apical membrane in cross-sections of 10 tubules. Morpho- and histometrical data were analyzed by ANOVA using the General Linear Model procedure of the SAS Institute, Inc [19]. Histometric data were co-variated for testicular and epididymal weight. The individual buffalo bull values were considered to be the experimental unit of all measured variables. The data were presented as least squared means \pm SEM. Differences between means were considered significant at $\mathrm{P}<0.05$.

\section{RESULTS}

The results obtained at the testicular and epididymal level showed season-related differences, even if accompanied by remarkable variations between individuals, indicated by high SEM values. Morphometric measures are summarized in Table 1, histometric data are summarized in Table $\mathbf{2}$.

Table 1. Morphometric Measures of Testis and Epididymis in the Two Different Seasons. Values are Expressed as Least Squared Means \pm SEM

\begin{tabular}{|l|c|c|c|}
\hline & $\begin{array}{c}\text { Mating } \\
\text { Season }\end{array}$ & $\begin{array}{c}\text { Non-Mating } \\
\text { Season }\end{array}$ & $\begin{array}{c}\boldsymbol{p} \\
\text { Value }\end{array}$ \\
\hline \hline Testis & & & \\
weight $(\mathrm{g})$ & $168.99 \pm 9.31$ & $165.99 \pm 10.75$ & 0.643 \\
major diameter $(\mathrm{cm})$ & $10.24 \pm 0.24$ & $9.88 \pm 0.28$ & 0.390 \\
minor diameter $(\mathrm{cm})$ & $5.64 \pm 0.22$ & $5.97 \pm 0.26$ & .0386 \\
\hline Epididymis & & & \\
weight $(\mathrm{g})$ & $32.26 \pm 3.89$ & $35.89 \pm 4.49$ & 0.568 \\
length caput-cauda $(\mathrm{cm})$ & $16.99 \pm 0.91$ & $13.88 \pm 1.05$ & 0.076 \\
cauda diameter $(\mathrm{cm})$ & $2.36 \pm 0.07$ & $2.33 \pm 0.08$ & 0.845 \\
\hline
\end{tabular}

Table 2. Histometric Measures of Testis and Epididymis in the Two Different Seasons. The Values, Co-Variated for the Respective Weight of the Organs, are Expressed as Least Squared Means \pm SEM. Significant Differences are Underlined

\begin{tabular}{|l|c|c|c|}
\hline & $\begin{array}{c}\text { Mating } \\
\text { Season }\end{array}$ & $\begin{array}{c}\text { Non-Mating } \\
\text { Season }\end{array}$ & $\begin{array}{c}\boldsymbol{p} \\
\text { Value }\end{array}$ \\
\hline \hline $\begin{array}{l}\text { Testis } \\
\text { sem. tub diameter }(\mu \mathrm{m})\end{array}$ & $243.19 \pm 1.75$ & $211.77 \pm 20.3$ & $\underline{\leq 0.001}$ \\
\hline $\begin{array}{l}\text { Epididymis - corpus } \\
\text { diameter }(\mu \mathrm{m})\end{array}$ & $393.99 \pm 8.97$ & $343.64 \pm 10.42$ & $\underline{0.0006}$ \\
epithelial highness $(\mu \mathrm{m})$ & $90.45 \pm 2.37$ & $86.83 \pm 2.75$ & 0.3310 \\
\hline $\begin{array}{l}\text { Epididymis - cauda } \\
\text { diameter }(\mu \mathrm{m})\end{array}$ & $675.81 \pm 15.52$ & $687.23 \pm 18.01$ & 0.6380 \\
epithelial highness $(\mu \mathrm{m})$ & $45.01 \pm 1.30$ & $52.50 \pm 1.51$ & $\underline{0.0005}$ \\
\hline
\end{tabular}

Figs. (1-3) show the histological aspect of the testis and epididymis in the two reproductive seasons, as well as examples of the histometrical evaluations in the organs considered.

Mean testicular weights and the main diameter of the organ were higher during the mating period than during the non-mating period (Table 1). Histological evaluation of 

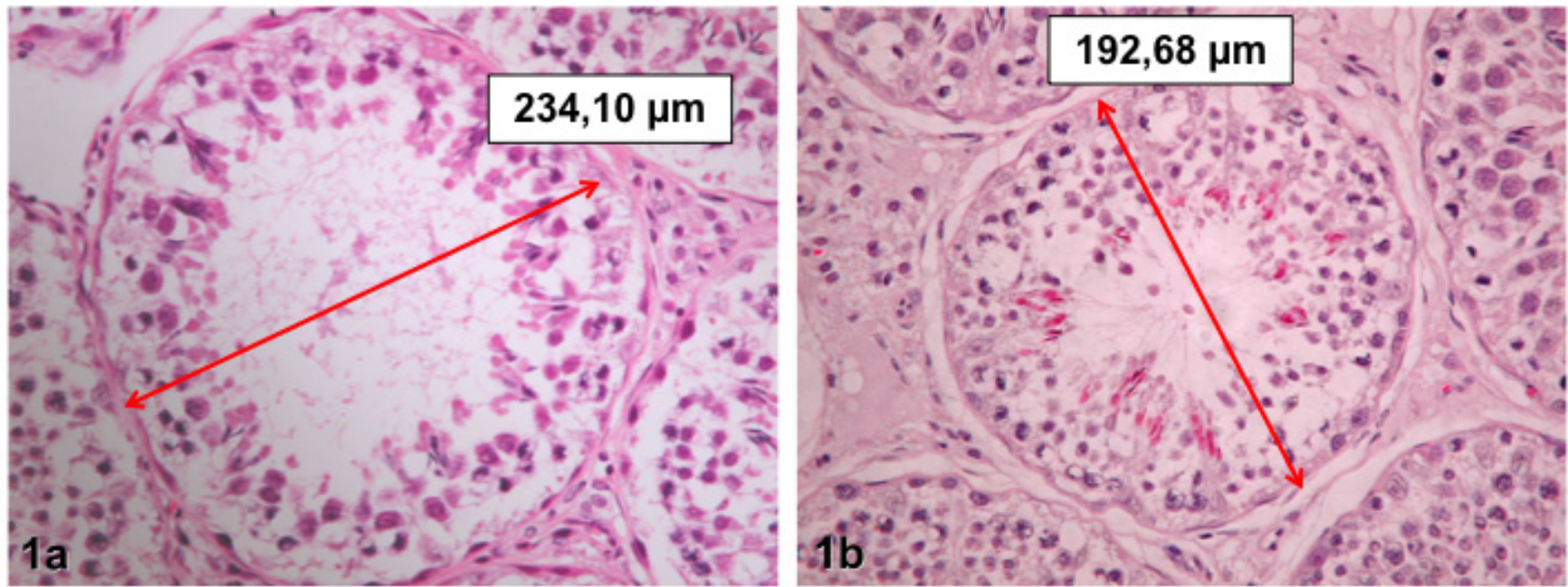

Fig. (1). Buffalo testis (a: mating season, b: non-mating season). An example of histometric measurements of seminiferous tubules diameter is shown, with relative measures. H\&E staining. Original magnification $400 \mathrm{x}$.
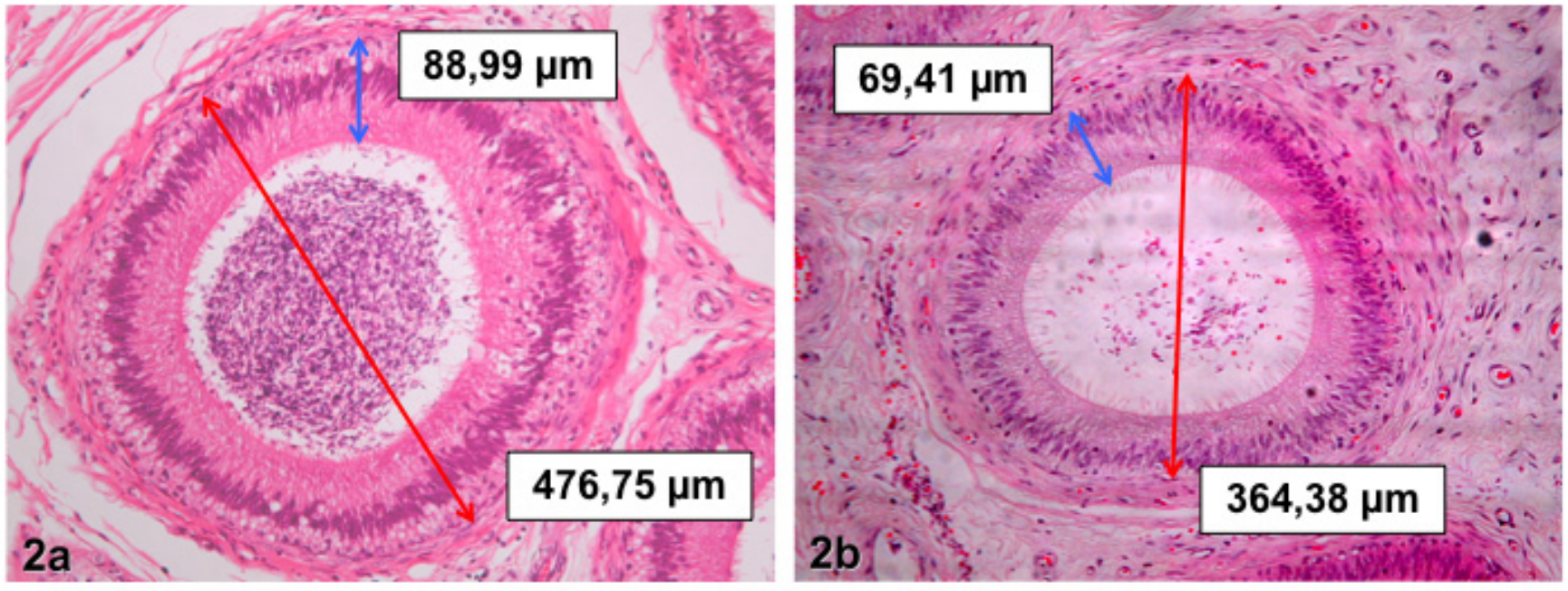

Fig. (2). Buffalo epididymis, corpus (a: mating season, b: non-mating season). An example of histometric measurements is shown: red lines indicate tubular diameter, blue lines epithelial cell height. H\&E staining. Original magnification 200x.
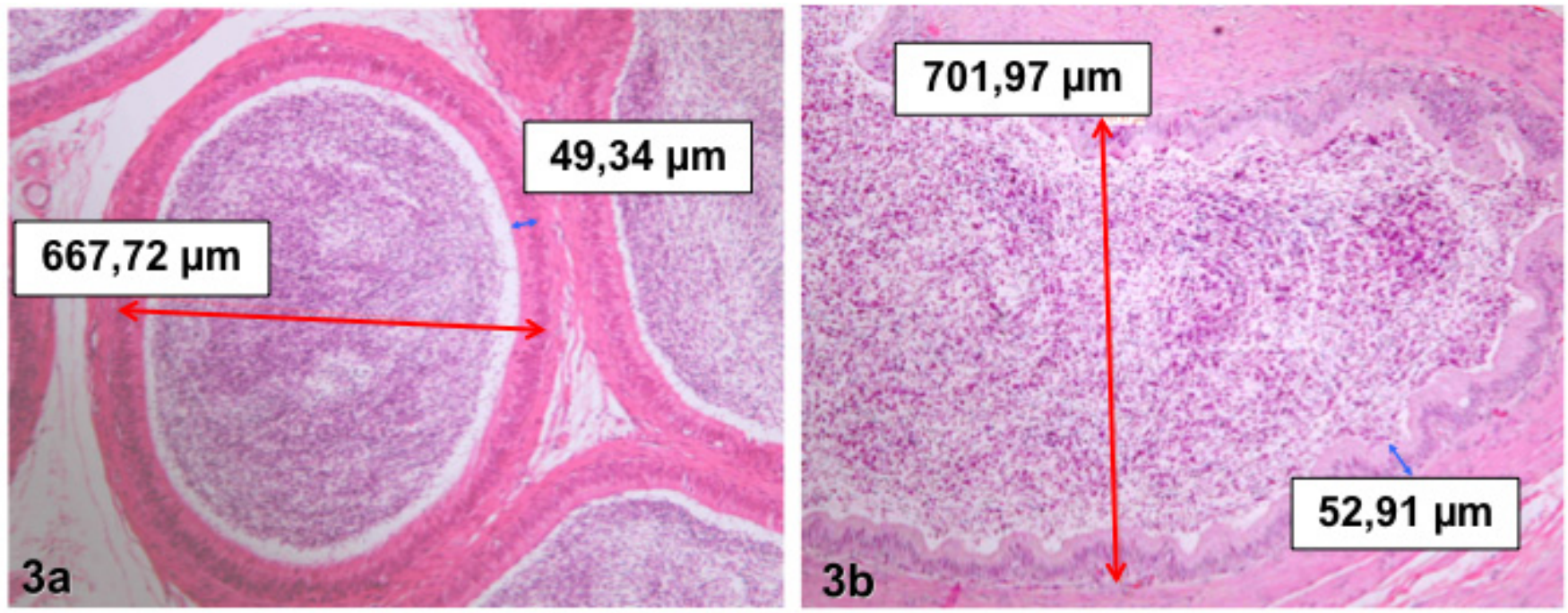

Fig. (3). Buffalo epididymis, cauda (a: mating season, b: non-mating season). An example of histometric measurements is shown: red lines indicate tubular diameter, blue lines epithelial cell height. H\&E staining. Original magnification 100x. 
testicular seminiferous tubules showed that the spermatogenesis was conserved also in the resting period (Fig. 1). The epididymal weight was slightly increased in the non-mating season, but the difference versus the mating period was not statistically significant (Table 1). The histological organization and structure of epididymis was generally unaffected by time of tissue collection, and intraluminal spermatozoa were present in all the sections (Figs. 2, 3).

The statistical analyses of the mean histometrical measures obtained in the two different experimental situations took into account the respective weight of the organs considered, in such a way to formulate the comparison independent from high individual variability.

At the testicular level, tubular diameters were significantly smaller during the non-mating summer months (Table 2, Fig. 1). In the corpus of the epididymis, tubular diameter was significantly reduced in summer. Epithelial cell height was also reduced during the non-mating season at the corpus level of the epididymis (Table 2, Fig. 2). On the contrary, in the epididymal cauda tubular diameter and epithelial cell height increased during the summer (Table 2, Fig. 3).

\section{DISCUSSION}

In well nourished buffalo bulls with a good body condition score, testicular spermatogenic cell divisions start by approximately 12 months of age and active spermatogenesis can be seen from 15 months. However, the ejaculate contains viable spermatozoa only after 24-30 months of age [5], indicating that male buffalo matures more slowly than male cattle [1] and has a longer time lag between onset of spermatogenesis and the achievement of puberty. Thereafter, even if capable of breeding throughout the year, buffalo bulls are known to show seasonal rise and fall in reproductive functions, which have been recorded in most countries where this species is reared $[2,8,9,20]$. In our experiment, comparison of buffalo male reproductive organs collected in mating and non-mating seasons showed that morphological integrity was conserved either at testicular and at epididymal levels. Smaller testicular volumes, together with minor values of tubular diameters might indicate a decreased spermatogenesis. In addition, reduced epididymal tubular diameters at corpus level might indicate a lower functional sustainability of this organ, whose activities toward maturation and conservation of spermatozoa transiting in the lumen are well-known. The unvaried volume of epididymis in toto and the results obtained at the cauda level are apparently discordant. They might be explained, taking into account the recognized role of the cauda epididymidis in storing the non-ejaculated spermatozoa. In fact, during the non-mating season the lumen might possibly enlarge under the pressure of sperm accumulation, and the epithelium increase its functional role. For the same reason, the organ may be possibly augmented in weight during the non-mating season.

Circannual changes in reproductive organs were noticed in most parts of the male reproductive tract in the roe deer [14], demonstrating the interplay of the morphological state of all components of the reproductive tract and the production of spermatozoa, semen plasma and testosterone.
Also, in Murrah buffalo bulls, a significant positive relationship between scrotal circumference and semen volume and concentration per ejaculate was reported [15], indicating that in buffalo, as in cattle, scrotal circumference is a useful indicator of potential sperm output and may serve as an important criterion for selecting young bulls as A.I. sires.

\section{CONCLUSION}

In this study, histometry has proven to be a useful tool to make a comparisons between the two different reproductive periods of buffalo bulls. Data have been compared in an objective way where results could be clearly analysed.

In regard to the reproductive physiology of buffalo bulls, a number of cyclic transformations are observed, which concern the gonad and genital tract, with a diminished activity during late spring-summer. The study here performed gives suggestions of the morphological modifications occurring in the testis and epididymis in response to the different factors brought about by seasonal variations, that, starting from the retina and involving the pineal/hypothalamus/pituitary/gonadal axis, modulate the hormonal fluctuations which in turn influence the spermatogenesis process. Accordingly, recent studies of this research group confirm that some parameters of the ejaculated semen are deeply altered during the summer season [21,22], with an increase of sperm DNA damage in the summer period. Hormonal assays are in progress, too.

\section{ACKNOWLEDGEMENTS}

The slaughterhouse of Stabilimento Inalca, Ospedaletto Lodigiano (Lodi, Italy) is gratefully acknowledged for providing the specimens used in this study. This work was granted by Italian Ministry of Education, University and Research (MIUR).

\section{REFERENCES}

[1] Drost M. Bubaline versus bovine reproduction. Theriogenology 2007; 68: 447-9.

[2] Zicarelli L. Reproductive seasonality in buffalo. Bubalus bubalis 1997; IV/97 (Suppl): 29-52.

[3] Rosa HJD, Bryant MJ. Seasonality of reproduction in sheep. Small Ruminant Res 2003; 48: 155-71.

[4] Lincoln GA, Short RV. Seasonal breeding: nature's contraceptive. Recent Prog Horm Res 1980; 36: 1-52.

[5] Perera O BM. Reproduction in water buffalo: comparative aspects and implications for management. J Reprod Fertil Suppl 1999; 54 : 157-68.

[6] Perera BM. Reproduction in domestic buffalo. Reprod Domest Anim 2008; 43 (Suppl 2): 200-6.

[7] Barile VL. Improving reproductive efficiency in female buffaloes (Livest Prod Sci) 2005; 92: 183-94. Review.

[8] Sengupta BP, Misra MS, Roy A. Climatic environment and reproductive behaviour of buffaloes. I. Effect of different seasons on various seminal attributes. Indian J Dairy Sci 1963; 16, 150-65.

[9] Rajamahendran R, Sultan B. Effect of climatic environment on libido and semen characteristics of buffalo bulls in Sri Lanka. Phil J Vet Anim Sci 1987; 9: 260

[10] Bahga CS, Khokar BS. Effect of different seasons on concentration of plasma luteinizing hormone and seminal quality vis-à-vis freezability of buffalo bulls (Bubalus bubalis). Int J Biometeorol 1991; 35: 222-4.

[11] Seren E, Parmeggiani A. Oestrus cycle in Italian buffalo. Bubalus bubalis 1997; IV/97 (suppl): 21-8.

[12] Drost M. Advanced reproductive technology in the water buffalo. Theriogenology 2007; 68: 450-3. 
[13] Yasuo S, Nakao N, Ohkura S, et al. Long-day suppressed expression of type 2 deiodinase gene in the mediobasal hypothalamus of the Saanen goat, a short-day breeder: implication for seasonal window of thyroid hormone action on reproductive neuroendocrine axis. Endocrinology 2006; 147: 432-40.

[14] Goeritz F, Quest M, Wagener A, et al. Seasonal timing of sperm production in roe deer: interrelationship among changes in ejaculate parameters, morphology and function of testis and accessory glands. Theriogenology 2003; 59: 1487-502.

[15] Pant HC, Sharma RK, Patel SH, et al. Testicular development and its relationship to semen production in Murrah buffalo bulls. Theriogenology 2003; 60: 27-34.

[16] Gatti JL, Castella S, Dacheux F, et al. Post-testicular sperm environment and fertility. Anim Reprod Sci 2004; 82/83: 321-39.

[17] Cornwall GA. New insights into epididymal biology and function. Hum Reprod 2009; 15: 213-27.

[18] Monfort SL, Brown JL, Bush M, et al. Circannual interrelationships among reproductive hormones, gross morphometry, behaviour, ejaculate characteristics and testicular histology in Eld's deer stags (Cervus eldi thamin). J Reprod Fertil 1993; 98: 471-80.

[19] SAS/STAT. User's Guide, release 603, 1985 ed., (SAS Institute, Inc., Cary, NC, USA).

[20] Esposito L, Campanile G, Di Palo R, Boni R, Di Meo C, Zicarelli L. Seasonal reproductive failure in buffaloes bred in Italy. In: Proceedings of the Twelfth International Congress, The Hague, The Netherlands, Anim Reprod (ICAR) 1992; 4: 2045-7.

[21] Stacchezzini MC, Gliozzi TM, Stacchezzini S, Pozzaglio C, Arrighi S, Cremonesi F. DNA integrity evaluated by Comet Assay in Buffalo (Bubalus bubalis) sperm during winter and spring (Preliminary results). Proceedings of the 1st Buffalo Symposium of the Europe and Americas, 2005, Oct 13-16 Paestum (Sa), Italy.

[22] Gliozzi TM, Stacchezzini MC, Arrighi S, Cremonesi F. Seasonal Variation of DNA Integrity Assessed by Comet Assay in Buffalo (Bubalus bubalis). Reprod Dom Anim, 41, 311 (absP3), Proceedings of the $10^{\text {th }}$ Annual ESDAR Conference, 2006.

(C) Arrighi et al.; Licensee Bentham Open.

This is an open access article licensed under the terms of the Creative Commons Attribution Non-Commercial License (http://creativecommons.org/licenses/by-nc/ 3.0/) which permits unrestricted, non-commercial use, distribution and reproduction in any medium, provided the work is properly cited. 